\title{
Combining Colistin and Fluconazole Synergistically Increases Fungal Membrane Permeability and Antifungal Cidality
}

\author{
Maayan Bibi, Sarah Murphy, Raphael I. Benhamou, Alex Rosenberg, Adi Ulman, Tihana Bicanic, \\ Micha Fridman, and Judith Berman*
}

Cite This: https://dx.doi.org/10.1021/acsinfecdis.0c00721

Read Online

ACCESS |

山ll Metrics \& More

Article Recommendations

S1 Supporting Information

\begin{abstract}
The increasing emergence of drug-resistant fungal pathogens, together with the limited number of available antifungal drugs, presents serious clinical challenges to treating systemic, lifethreatening infections. Repurposing existing drugs to augment the antifungal activity of well-tolerated antifungals is a promising antifungal strategy with the potential to be implemented rapidly. Here, we explored the mechanism by which colistin, a positively charged lipopeptide antibiotic, enhances the antifungal activity of

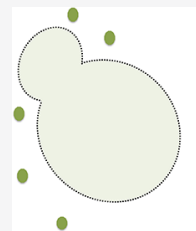

. - Colistin

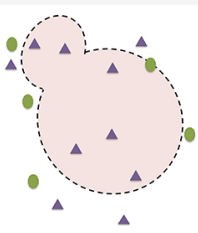

fluconazole + colistin low concentration/early fluconazole + colistin fluconazole, the most widely used orally available antifungal. In a range of susceptible and drug-resistant isolates and species, colistin was primarily effective at reducing fluconazole tolerance, a property of subpopulations of cells that grow slowly in the presence of a drug and may promote the emergence of persistent infections and resistance. Clinically relevant concentrations of colistin synergized with fluconazole, reducing fluconazole minimum inhibitory concentration 4-fold. Combining fluconazole and colistin also increased survival in a C. albicans Galleria mellonella infection, especially for a highly fluconazole-tolerant isolate. Mechanistically, colistin increased permeability to fluorescent antifungal azole probes and to intracellular dyes, accompanied by an increase in cell death that was dependent upon pharmacological or genetic inhibition of the ergosterol biosynthesis pathway. The positive charge of colistin is critical to its antifungal, and antibacterial, activity: colistin directly binds to several eukaryotic membrane lipids (i.e., L- $\alpha$-phosphatidylinositol, L- $\alpha$-phosphatidyl-L-serine, and L- $\alpha$ phosphatidylethanolamine) that are enriched in the membranes of ergosterol-depleted cells. These results support the idea that colistin binds to fungal membrane lipids and permeabilizes fungal cells in a manner that depends upon the degree of ergosterol depletion.
\end{abstract}

KEYWORDS: colistin, antifungal, azole, yeast, ergosterol synthesis, membrane permeabilization

C andidemia, the fourth most common hospital-acquired infection in the United States, is associated with an attributable mortality of up to $40 \%^{1}$ and is most frequently caused by Candida albicans (38\%). ${ }^{2}$ Only three classes of antifungal drugs are used systemically, largely because of the paucity of fungal-specific drug targets. Repurposing known drugs (e.g., chemosensitizers) that are able to synergize with existing antifungal drugs is an approach for the rapid development of improved therapeutic strategies. ${ }^{3,4}$

The azoles, the most commonly used antifungal drug class, ${ }^{5}$ target the biosynthesis of ergosterol (a sterol not found in animals or plants), by inactivating lanosterol $14 \alpha$-demethylase, which is encoded by the ERG11 gene. ${ }^{6}$ Fluconazole is the most commonly used azole antifungal and is fungistatic rather than fungicidal for yeasts. ${ }^{5}$ Emerging species with higher levels of fluconazole resistance (e.g., Candida glabrata and Candida auris) are increasingly prevalent. ${ }^{5}$ In addition, susceptible isolates can have high levels of fluconazole tolerance, which appears to reduce the efficacy of fluconazole monotherapy. ${ }^{7,8}$

Antifungal resistance is the ability to grow normally in the presence of drug at concentrations that inhibit other isolates of a given species, which is usually due to genetic changes that affect all cells in the population. Mechanisms of antifungal resistance include those that prevent or inhibit binding of the drug to its target, including reduction in target affinity, and decreased intracellular drug concentration due to membrane permeability changes and/or drug efflux. ${ }^{9}$ Clinical breakpoints identify isolates whose minimal inhibitory concentration (MIC) exceeds the drug concentration reached during treatment (reviewed in ref 8).

Antifungal tolerance is the ability of some cells in the population to grow slowly despite high drug concentrations and is characterized by slow growth of a subpopulation of cells after $48 \mathrm{~h}$ of growth in drug, where resistance is generally evident after $24 \mathrm{~h}$ in the same conditions. Since standard

Received: October 14, 2020 
clinical assays measure growth at $24 \mathrm{~h}$, strains with tolerance are classified as drug-susceptible. Tolerance is measured, where the fraction of growth (FoG) is quantitated as the degree of growth within vs outside the zone of inhibition. ${ }^{10}$ Alternatively, tolerance can be quantitated using broth microdilution assays. $^{7,10}$ The level of tolerance in a given isolate is reproducible and differs from that in other isolates. This is presumably due to differences in genetic backgrounds, as multiple stress response pathways contribute to tolerance. ${ }^{7}$ However, within a given genetic isolate, the responses of individual cells differ, such that the tolerance response is generally considered to be physiological, or epigenetic, rather than a genetic change. ${ }^{8}$ Several recent studies suggest high levels of tolerance have a negative effect on clinical outcomes. ${ }^{7,11,12}$

A common drug-resistance mechanism is hyperactivation of efflux pumps, although drug uptake rates may also affect the efficacy of antifungal drugs that target intracellular molecules. Several studies suggest that azoles enter cells via passive diffusion because cells with higher membrane fluidity were more susceptible to the drug. ${ }^{13-15}$ Earlier studies of azole uptake in C. albicans utilized tritiated fluconazole ( $\left[{ }^{3} \mathrm{H}\right]$-FLC) and ketoconazole $\left(\left[{ }^{3} \mathrm{H}\right]-\mathrm{KTZ}\right)^{16,17}$ to measure intracellular drug content, which reflects the balance between drug uptake, and drug efflux. Internalization of the tritiated drugs occurred rapidly in live, but not dead cells, while dead cells accumulated propidium iodide stain. ${ }^{16}$ In glucose-depleted, de-energized cells, $\left[{ }^{3} \mathrm{H}\right]$-FLC accumulated and reached saturation, and competition assays suggested that the same transporter is used for different azole antifungals. Taken together, these data suggested that the mechanism of drug uptake was not via passive diffusion. ${ }^{16}$

Several adjuvant drugs, when used together with fluconazole, reduce tolerance to background levels without having a major effect on drug resistance (MIC). ${ }^{4}$ These include drugs that affect the calcineurin pathway, Hsp90 activity, the target of rapamycin (TOR) pathway and other stress responses. ${ }^{18}$ Importantly, adding any one of these adjuvants to fluconazole (a fungistatic drug) renders it fungicidal: cells exposed to supra-MIC FLC concentrations together with the adjuvant do not survive. ${ }^{7}$ Thus, a number of drugs sensitize Candida cells to fluconazole by modulating their stress response pathways.

Colistin, also known as polymyxin E, belongs to the lipopeptide class of antibiotics (with polymyxin B being the other polymyxin used clinically) and targets lipopolysaccharides within the membranes of Gram-negative bacteria. ${ }^{19}$ It is a cationic cyclic polypeptide with a hydrophobic fatty acid acyl chain that interacts electrostatically with the anionic phosphate groups of the lipid A core of lipopolysaccharide (LPS) molecules in the outer leaflet of the outer membrane of Gram-negative bacteria. $^{20,21}$ Colistin is increasingly used to treat multidrug-resistant Gram-negative bacterial infections ${ }^{22}$ despite its nephrotoxicity and neurotoxicity. ${ }^{23}$ By competitively displacing divalent cations $\left(\mathrm{Ca}^{2+}\right.$ and $\mathrm{Mg}^{2+}$ ) from the phosphate groups of membrane lipids, colistin targets LPS in the outer membrane replacing the bivalent cations that stabilize the outer leaflet of the outer membrane groups, resulting in membrane leakage and bacterial death. ${ }^{24-26}$ Colsitin is generally not considered an antifungal drug, although it has weak antifungal activity in Candida tropicalis ${ }^{27}$ and when used in combination with the azole isavuconazole in C. auris. $^{28}$
Colistin was reported to synergize with azole antifungals against Candida and Cryptococcal isolates. ${ }^{29,30}$ However, prior studies used high levels of colistin that are not readily achieved in patients. ${ }^{27,31,32}$ For example, C. albicans cidality was reported with $6-8 \mu \mathrm{g} / \mathrm{mL}$ polymyxin B added to $64 \mu \mathrm{g} / \mathrm{mL}$ fluconazole, which is well above the concentration that is reached in patients. $^{30}$ Furthermore, the mechanism(s) by which colistin synergizes with azoles is not known: Do they work on eukaryotes via mechanism(s) like those that confer antibacterial activity? And why are they synergistic with the azole antifungals?

Here, we studied how colistin synergizes with azole antifungals. We found that this synergism caused a major reduction in azole tolerance both in vitro and in vivo with only a modest effect on antifungal resistance at concentrations that are clinically relevant. Importantly, the mechanism of action of colistin is membrane permeabilization and subsequent cell death in cells that are depleted for ergosterol, either by azole drug treatment or by mutations in the ergosterol biosynthesis pathway.

\section{RESULTS}

Combining Fluconazole and Colistin (FLC+COL) Reduces Drug Tolerance and Resistance in C. albicans Isolates and Other Pathogenic Yeasts. Colistin (COL) is known to enhance the antifungal efficacy of fluconazole (FLC), but whether this is largely due to a reduction in drug resistance or tolerance is unclear. Using disk diffusion assays with FLC $(25 \mu \mathrm{g})$ in the disk and COL $(64 \mu \mathrm{g} / \mathrm{mL})$ in the agar medium, we measured both resistance/susceptibility and tolerance to FLC using diskImageR, ${ }^{10}$ an image analysis pipeline that quantifies resistance/susceptibility as the radius (in $\mathrm{mm}$ ) of the zone of inhibition at $20 \%$ inhibition $\left(\mathrm{RAD}_{20}\right)$ after $24 \mathrm{~h}$ and the fraction of growth $\left(\mathrm{FoG}_{20}\right)$ within the zone of inhibition at 48 h. ${ }^{7,10}$ The addition of COL reduced $F_{0 G}$ to background levels, (i.e., levels seen with very low tolerance strains), while $\mathrm{RAD}_{20}$ increased only modestly (by $\sim 3.5 \mathrm{~mm}$ ) (Figure $1 \mathrm{~A}$ and B). Thus, combining COL with FLC primarily reduced tolerance in strain SC5314, the standard lab strain.

To determine the generalizability of the effect, we performed similar analyses on a collection of clinical isolates representing the four major C. albicans clades, which exhibit FLC tolerance levels measured as FoG ranging from $<30 \%$ to $>80 \%{ }^{7}$ (Figure 1C). Notably, COL cleared FoG to near-baseline levels, in a manner that correlated with the initial FoG levels (Figure 1C) (FoG levels for FLC vs FLC+COL, with coefficient of determination $\left(R^{2}\right)$ of 0.92 . COL+FLC had a similar effect in $C$. albicans strains reported to be resistant to FLC as well as for representative isolates from other pathogenic species and for wild isolates of Saccharomyces cerevisiae (Figure S1), causing a slight increase in $\mathrm{RAD}$ /susceptibility and dramatic clearance of FoG/tolerance). Thus, COL appears to affect very different yeast strains in an analogous manner.

Effect of Colistin on Other Antifungal Drugs. Because $\mathrm{COL}$ was reported to affect several antifungal drugs, we first tested the degree to which COL enhanced the activity of azole drugs that, like FLC, inhibit sterol biosynthesis. Like with FLC, COL added to ketoconazole, itraconazole, posaconazole or miconazole only slightly increased the susceptibility level $(2-5$ $\mathrm{mm}$ ) (Figure S2) and cleared $\mathrm{FoG}_{20}$ to baseline levels. Interestingly, with terbinafine, a drug that inhibits Erg1 catalysis, the first step in the ergosterol biosynthesis pathway, COL completely eliminated FoG and increased susceptibility 
A

B

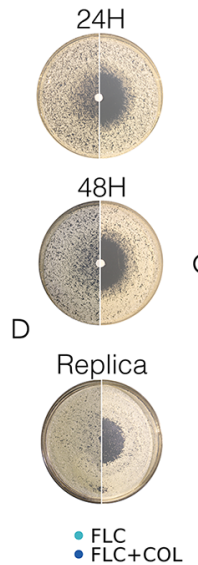

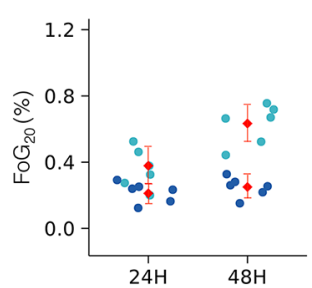

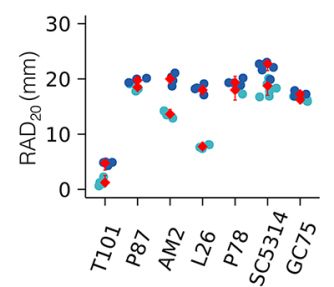

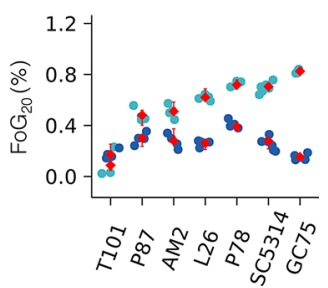

Figure 1. Colistin clears antifungal tolerance measured by disk diffusion assays. (A) Images of disk diffusion assays using FLC disks $(25 \mu \mathrm{g} /$ disk $)$ with strain SC5314, performed without (left) or with (right) the addition of COL $(64 \mu \mathrm{g} / \mathrm{mL})$ and imaged after 24 and 48 h (upper and lower panels, respectively). (B and C) Summaries of disk diffusion assays quantified by diskImage $R^{10}$ for the radius of the zone of inhibition $\left(\mathrm{RAD}_{20}\right)$ (left panels, in $\mathrm{mm}$ ) and the fraction of growth (FoG, right panels) in the absence (light blue dots) and presence (dark blue dots) of fluconazole. Red dots, mean; red error bars, standard deviation. (C) Assays performed with C. albicans isolates having a range of different genetic backgrounds (see Table $1)^{7}$ (D) To test viability of cells across the plate in lower panel (A), this plate was transferred to a YPAD plate with no drug by replicaplating and imaged after $24 \mathrm{~h} . n=3$ biological and 2 technical replicates per isolate.

$\left(\mathrm{RAD}_{20}\right)$ by $7 \mathrm{~mm}$ (Figure S2C). By contrast, we detected only minor effects of COL on the resistance levels of echinocandin and polyene classes of antifungal drugs. In addition, there was little effect of COL on sphingolipid inhibitors and on 5fluorocytosine, an inhibitor of nucleotide biosynthesis (Figure S3). Thus, colistin appears to have a minor effect on resistance to most antifungal agents, and a more dramatic effect on azole tolerance.

Colistin Acts Synergistically with Antifungal Triazoles. We next asked whether the effect of COL on FLC is synergistic or additive, using checkerboard assays. ${ }^{33}$ The two drugs were combined in a series of 2 -fold dilutions from 0 to $128 \mu \mathrm{g}$ (Figure 2A). In combination with $0.25 \mu \mathrm{g} / \mathrm{mL}$ FLC, 2 $\mu \mathrm{g}$ COL was sufficient to reduce growth 2 -fold and adding 8 $\mu \mathrm{g} / \mathrm{mL} \mathrm{COL}$ reduced growth by 4 -fold (Figure $2 \mathrm{~B}$ ). The FICI (fraction inhibitory concentration index) value was 0.31 for $0.125 \mu \mathrm{g} / \mathrm{mL}$ FLC and $8 \mu \mathrm{g} / \mathrm{mL}$ COL, which is well within the range of clinically relevant concentrations and indicates synergy (FICI < 0.5). ${ }^{34,35}$ This FICI value $(0.31)$ was higher than that measured for $0.125 \mu \mathrm{g} / \mathrm{mL}$ COL used together with $0.39 \mu \mathrm{g} / \mathrm{mL}$ of echinocandin (caspofungin) in C. albicans $\left(\right.$ FICI $\left.=0.26^{29}\right)$. Similarly, for itraconazole and COL, FICI = 0.28 was measured (Table $1,0.125 \mu \mathrm{g} / \mathrm{mL}$ itraconazole, $4 \mu \mathrm{g} /$ $\mathrm{mL}$ of COL) (Figure S4). Thus, COL is synergistic with different antifungal triazoles at levels of both drugs that are clinically achieveable. ${ }^{36,37}$

Combination Therapy Using Colistin with Fluconazole Increased Cidality. We next asked if COL, like other adjuvants that eliminate tolerance, increases the level of FLC cidality in vitro, ${ }^{7}$ using two approaches. First, we tested if cells in the zone of inhibition could resume growth by replica-

plating disk diffusion assay plates to rich medium (YPD) without either drug (Figure 1D). Cells on plates exposed only to the FLC disk produced a lawn of cells within, as well as outside, the zone of inhibition, consistent with the static nature of FLC alone. By contrast, the disk diffusion assays plates that had included COL, when replica-plated to rich medium, were essentially clear within the zone of inhibition (Figure 1D), indicating that the cells treated with inhibitory concentrations of FLC were unable to regrow in the absence of the drug and were likely dead. Similar results were seen when COL was added to other inhibitors of sterol biosynthesis (Figure S2C). Thus, COL caused the death of cells exposed to azoles and other inhibitors of sterol biosynthesis, an essential process.

Second, we analyzed cells with propidium iodide (PI), a common indicator of cell death: ${ }^{38}$ Control live cells (no drug) excluded PI, and dead cells (killed with ethanol) stained very brightly with the dye. Both live and dead controls were used to set gating thresholds for flow cytometric analysis (Figure 2C): live cells had no detectable PI (less than $\sim 250$ arbitrary units (A.U) of fluorescence). Dead cells stained brightly with PI ( $>8500$ and up to $4.67 \times 10^{5} \mathrm{AU}$ of fluorescence), with $99.2 \%$ having PI $>8931$ AU.

The proportion of cells in each category was determined after $24 \mathrm{~h}$ of exposure to combinations of both drugs at concentrations ranging from 0 to $128 \mu \mathrm{g} / \mathrm{mL}$, as in the checkerboard assay (Figure 2A). Consistent with results from the initial checkerboard assay, the number of cells counted per $200 \mu \mathrm{L}$ reflected the $\mathrm{OD}_{600}$ measurements observed in the checkerboard in Figure 2A. The number of dead cells increased when FLC and COL were combined (Figure 2C, Red). These data support the idea that COL together with FLC not only inhibits cell growth but also increases cell death at inhibitory FLC concentrations (Figure 2C, red).

Combination of Fluconazole and Colistin Resulted in Enhanced Survival Relative to Fluconazole Monotherapy in Galleria mellonella. We then used the C. albicans-G. mellonella pathosystem to test FLC+COL efficacy in vivo for strains with different tolerance levels. G. mellonella were infected with a dose of $C$. albicans that gradually killed the larvae over a period of 5 days. Two hours post inoculation, larvae were treated with either water (control), FLC, COL, or $\mathrm{FLC}+\mathrm{COL}$ as a single dose (Figure $2 \mathrm{D}-\mathrm{F}$ ). Five day survival of the controls (for all three strains) was only $16-22 \%$. Survival of larvae infected with the high FoG strain and treated with FLC+COL (78\%) was significantly greater than either drug alone (FLC, 40\%; COL, 32\% survival). By contrast, adding colistin did not improve survival of the two strains with lower tolerance ( $56 \%$ and $64 \%$ survival on FLC+COL vs $68 \%$ and $72 \%$ survival on FLC alone). Overall, the tolerance level of the $C$. albicans strain was relevant, with high FoG (more tolerant) strains having more sensitivity to the drug combination.

Combining Colistin with Fluconazole Increases Cell Permeability to Propidium lodide. To explore the mechanism by which COL synergizes with FLC, we measured the dynamics with which cells died in PI, first by microscopy (Figures 3A,B and S6A), and determined the resulting CFU (Figure S6B) and then quantitatively by flow cytometry (Figures 3C and S7). As expected, cells not exposed to any drug did not take up PI and had buds of all sizes, while dead cells (killed with ethanol) stained brightly with PI (Figure 3A). Flow cytometric analysis of the PI found that live cells contained <239 AU (Figure 3B) and dead cells had >8931 AU 
A
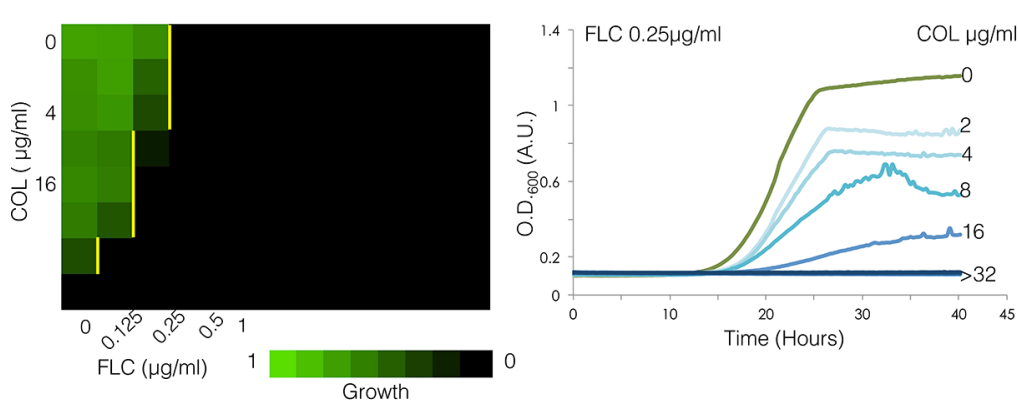

C
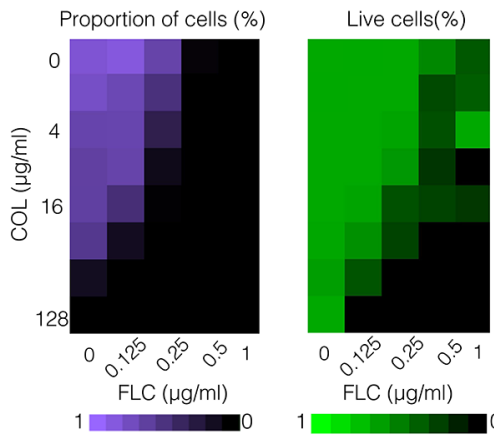

D

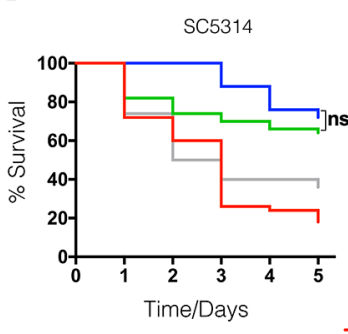

$\mathrm{E}$
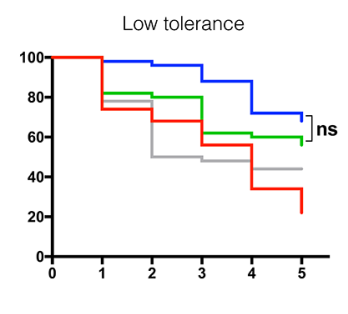

- Water - FLC - COL - FLC+COL

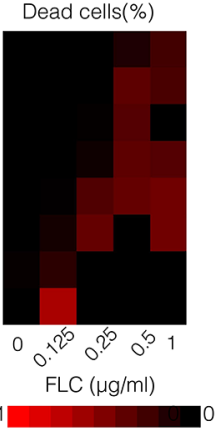

F

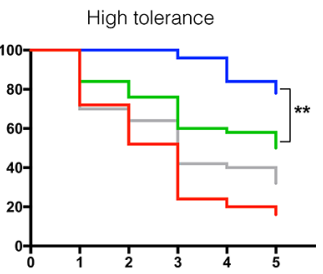

Figure 2. Colistin acts synergistically with fluconazole. (A) Checkerboard assay measuring O.D. ${ }_{600}$ for combinations of with FLC ( $X$ axis) and COL ( $Y$ axis) using 2 -fold dilutions $\left(0,0.125,0.25,0.50,1,2,4,8,16,32,64\right.$, and $128 \mu \mathrm{g} / \mathrm{mL}$ ). Color bar indicates growth based upon O.D. ${ }_{600}$ (yellow line, $\mathrm{MIC}_{50}$ for each drug combination) after $24 \mathrm{~h}$ of growth. CFU determination gave similar results. (B) Growth curves $(\mathrm{OD} 600)$ in $0.25 \mu \mathrm{g} / \mathrm{mL}$ FLC without or with COL $(0-128 \mu \mathrm{g} / \mathrm{mL})$. (C) Checkerboard assay analyzed after $24 \mathrm{~h}$ of growth by flow cytometry. Cells were stained with propidium iodide and analyzed by flow cytometry. The proportion of cells $/ \mathrm{mL}$ in drug normalized to the number of cells $/ \mathrm{mL}$ at $0 \mathrm{FLC}$ and $0 \mathrm{COL}$ is illustrated (left panel, purple). The proportion of live cells (middle), and the proportion of dead cells (right) out of the total cells in a given well were determined from the PI fluorescence (<239 AU for live cells) and $>8931$ AU for dead cells). (D-F) G. mellonella survival curves. Larvae were inoculated with $5 \times 10^{4}$ cells/larvae. Two hours postinfection, larvae were treated with water only (black line), a single dose of FLC alone (0.0125 $\mu \mathrm{g}$, light blue), COL alone $(0.8 \mu \mathrm{g}$, gray), or FLC+COL $(0.0125 \mu \mathrm{g}$ and $0.8 \mu \mathrm{g}$, respectively, dark blue). Survival was recorded every $24 \mathrm{~h}$ for 5 days. Each group represents 50 larvae $(N=50)$. Larvae were infected with (D) lab SC5314, (E) low FoG strain YJB-T3016, or (F) highly tolerant strain YJB-T3023. There was no significant difference between larvae treated with FLC alone or FLC and COL in either SC5314 or low FoG ( $p=$ 0.2154 and $p=0.11$, respectively). There was a significant increase in survival of Galleria inoculated with the highly tolerant strain and treated with the combination compared to FLC alone $(p<0.001$ log-rank).

of fluorescence. In general, cells exposed to only one of the drugs (FLC or COL) appeared very similar to untreated live cells (Figure 3A, green arrow), with intact membranes. This is consistent with the static nature of FLC and the fact that COL does not have substantial antifungal activity at clinically relevant drug concentrations. ${ }^{30}$

A small proportion of these cells did have discernible, but low levels of PI staining (Figure 3A, right panel, pink arrow), suggesting that they were partially permeable to the dye. The cells that stained light pink appeared to have intact membranes based on their DIC refraction, suggesting that, despite taking up low amounts of PI, they were alive. By contrast, cultures of cells treated with FLC+COL included live, unstained cells, the light pink "permeable" cells with low levels of PI, as well as many dead cells that stained brightly with PI (Figures 3A, right panel, red arrow; Figures $3 \mathrm{~B}$ and S6A). We do not know if these light pink cells are able to continue growing over long time periods or if they are cells that have begun to become dye-permeable and will eventually lose membrane integrity.

Analysis of PI uptake over time using flow cytometry revealed that the first cells that were permeable or dead appeared after $\sim 1 \mathrm{~h}$ and that the proportion of permeable + dead cells increased with time of incubation in the drug combination (Figure 3B). Cells with an intermediate level of PI staining (between 239 and 8931 AU by flow cytometry) appeared to be viable, in that they retained normal cell shapes (Figure 3A, pink arrow), appeared intact as judged by DIC refraction, and had buds of all sizes, similar to the live cells (green arrow). 
Table 1. Strains Used in This Study

\begin{tabular}{|c|c|c|c|c|}
\hline $\begin{array}{l}\text { strain } \\
\text { number }\end{array}$ & $\begin{array}{l}\text { strain name/ } \\
\text { alias }\end{array}$ & genotype & species & source \\
\hline YJB-T1 & SC5314 & wild-type & C. albicans & J. Ernst \\
\hline YJB-T50 & BG2 & wild-type & C. glabrata & 54 \\
\hline YJB-T99 & Wu284 & wild-type & C. dubliniensis & 55 \\
\hline YJB-T48 & 660 & wild-type & C. tropicalis & P. T. Magee \\
\hline YJB-T90 & ATCC22109 & wild-type & C. parapsilosis & 56 \\
\hline YJB-T361 & L26 & MTL $a / a$ & C. albicans & 57 \\
\hline YJB-T363 & P87 & MTL $a / a$ & C. albicans & 57 \\
\hline YJB-T367 & GC75 & MTL alpha/alpha & C. albicans & 57 \\
\hline YJB-T379 & P78042 & MTL a/alpha & C. albicans & 57 \\
\hline YJB-T487 & $\mathrm{T} 101$ & MTL $a / a$ & C. albicans & 58 \\
\hline YJB-T512 & AM2003.0165 & $M T L \alpha / \alpha$ & C. albicans & 58 \\
\hline YJB-T111 & & wild-type figure isolate & $\begin{array}{l}\text { Saccharomyces } \\
\text { cerevisiae }\end{array}$ & 59 \\
\hline YJB-T113 & & wild-type vineyard isolate & S. cerevisiae & 59 \\
\hline YJB-T47 & & wild-type clinical isolate & $\begin{array}{l}\text { Candida } \\
\text { guilliermondii }\end{array}$ & 60 \\
\hline YJB-T1135 & $\operatorname{erg} 11 D 3-2$ & $\begin{array}{l}\text { ura3 } \Delta:: \lambda i m m 434 / \text { ura3 } \Delta:: \lambda i m m 434 \text { his1::hisG/his1::hisG arg4::hisG/arg4::hisG,erg11/ } \\
\quad \operatorname{erg} 11\end{array}$ & C. albicans & 61 \\
\hline YJB-T3 & FH5 & Clinical series isolate, acquired $i(5 L)$ & C. albicans & 62 \\
\hline YJB-T4 & FH8 & FH5, $i(5 L)$ with distal deletion & C. albicans & 62 \\
\hline YJB-T572 & BWP17 ERG11 & $\begin{array}{l}\text { ura3 } \Delta:: \lambda i m m 434 / \text { ura3 } \Delta:: \lambda i m m 434 \text { his1::hisG/his1::hisG arg4::hisG/arg4::hisG ERG11- } \\
\quad \text { URA2::RP10 locus }\end{array}$ & C. albicans & this study \\
\hline YJB-T573 & YMG9517 & $\underline{\mathrm{FH} 5} . \operatorname{erg} 11:: N A T 1$ & C. albicans & 63 \\
\hline YJB-T532 & DSY3987 & $\overline{\text { ura3 }} \Delta:: F R T /$ ura3 $\Delta:: F R T$, TAC1-5/TAC1-5, ERG11-5/ERG11-5, RP10::Clp10 & C. albicans & 29 \\
\hline YJB-T736 & SN152 & $\begin{array}{l}\text { SC5314 leu2 } \Delta / \text { leu } 2 \Delta \text { his } 1 \Delta / \text { his } 1 \Delta \arg 4 \Delta / \arg 4 \Delta U R A 3 / \text { ura3 } \Delta:: i m m 434 \text { IRO1/ } \\
\text { iro } 1 \Delta:: \text { imm } 434\end{array}$ & C. albicans & 64 \\
\hline YJB-T737 & BV06 & SN152 erg2 $\Delta::$ C.d.HIS1/erg2 $\Delta: C . m . L E U 2$ & C. albicans & 65 \\
\hline YJB-T738 & BV07 & SN152 $\operatorname{erg} 3 \Delta:: C . d . H I S 1 / \operatorname{erg} 3 \Delta: C . m . L E U 2$ & C. albicans & 65 \\
\hline YJB-T739 & BV08 & $\mathrm{SN} 152 \operatorname{erg} 4 \Delta::$ C.d.HIS1/erg $4 \Delta:$ C.m.LEU2 & C. albicans & 65 \\
\hline YJB-T740 & BV09 & SN152 erg5 $5:: C . d . H I S 1 / \operatorname{erg} 5 \Delta: C . m . L E U 2$ & C. albicans & 65 \\
\hline YJB-T741 & BV10 & SN152 $\operatorname{erg} 6 \Delta:: C . d . H I S 1 / \operatorname{erg} 6 \Delta: C . m . L E U 2$ & C. albicans & 65 \\
\hline YJB-T742 & BV11 & SN152 $\operatorname{erg} 3 \Delta::$ C.d.HIS1/erg3 $\Delta:$ C.m.LEU2 $\operatorname{erg} 11 \Delta: C . d . A R G 4 / \operatorname{erg} 11 \Delta / C . d . A R G 4$ & C. albicans & 65 \\
\hline YJB-T743 & BV12 & SN152 $\operatorname{erg} 24 \Delta:: C . d . H I S 1 / \operatorname{erg} 24 \Delta: C . m . L E U 2$ & C. albicans & 65 \\
\hline YJB-T3015 & SC5314 & direct wild-type parent of YJB-T3016 and YJB-T3023 & C. albicans & R. Bennett \\
\hline YJB-T3016 & Low FoG & YJB-T3015 passaged 12 days in YPD without drug A & C. albicans & J. Ene \\
\hline YJB-T3023 & High FoG & YJB-T3016 passaged 12 days in YPD $+1 \mu \mathrm{g} / \mathrm{mL}$ fluconazole D & C. albicans & J. Ene \\
\hline
\end{tabular}

Using flow cytometry, we quantified intracellular PI fluorescence dynamics over $3 \mathrm{~h}$ after the addition of PI (Figure 3B). As expected, the proportion of dead cells (PI staining $>8931$ units) increased with increasing amounts of the two drugs. In all FLC+COL treatments, dead cells first appeared at $\sim 60 \mathrm{~min}$ after adding the two drugs. Notably, the number of cells that were partially permeable to PI (239-8931 AU) was evident in all combinations of FLC+COL concentrations (Figure 3C). Together, these results indicate that combining FLC and COL synergistically increases cell permeability as well as cell death, two effects rarely seen with either drug alone.

To determine whether FLC+COL caused a general effect on cell permeability, we tested cell permeability in other stains, such as mitotracker green, which enters cells and stains mitochondrial membranes. The fluorescence intensity of intracellular mitotracker green became far brighter in the FLC+COL drug combination $(P$-value $<0.012)$ compared to a slight increase in FLC alone $(P$-value $<0.07)$ relative to no drug or COL only controls (Figure S7), suggesting that its permeability was increased in the FLC+COL treated cells. By contrast, no significant change in the intensity of calcofluor white staining of the outer cell wall (which does not require membrane permeabilization) was detectable ( $P$-value $>0.4-$
0.7, Figure S7), indicating that the change does not affect the ability of the cell wall to bind calcofluor. Thus, the FLC+COL combination appears to generally affect plasma membrane permeability, allowing more stain, and perhaps more drug, to enter the cells.

Fluorescent antifungal drug probes facilitate studies of drug uptake and intracellular localization. We established a series of fluorescent azole probes, ${ }^{39-41}$ including azole-dansyl and azole-Cy5, both of which localize primarily to the mitochondria, suggesting that some antifungal azole drugs may accumulate in the mitochondria. ${ }^{39}$ These probes are also useful for measuring net intracellular azole concentrations. Because FLC+COL together cause a general increase in cell permeability (e.g., permeability to mitotracker green), we asked if COL also affects the ability of FLC to cross the cell membrane. For this, we used azole-Cy5, a fluorescent azole antifungal probe that retains antifungal activity, is readily taken up by cells, and can be quantified by flow cytometry. ${ }^{39}$ Adding COL to azole-Cy5 accelerated the rate of Cy5-azole uptake by 2 -fold after $30 \mathrm{~min}$ of COL addition, relative to the level of the probe uptake in the absence of COL (Figure S5). This implies that the FLC+COL combination causes cells to reach higher intracellular concentrations of the azole, presumably because of increased membrane permeability. 


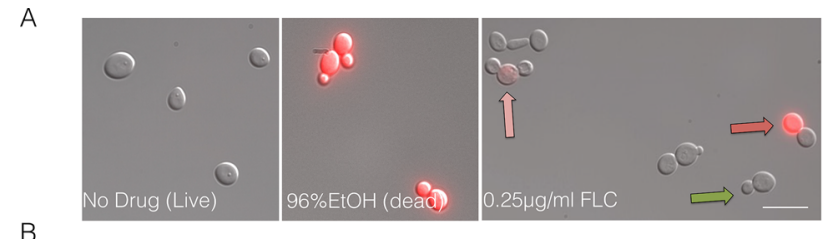

B

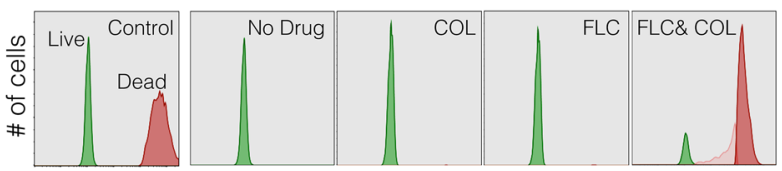

$\mathrm{PI}$ intensity
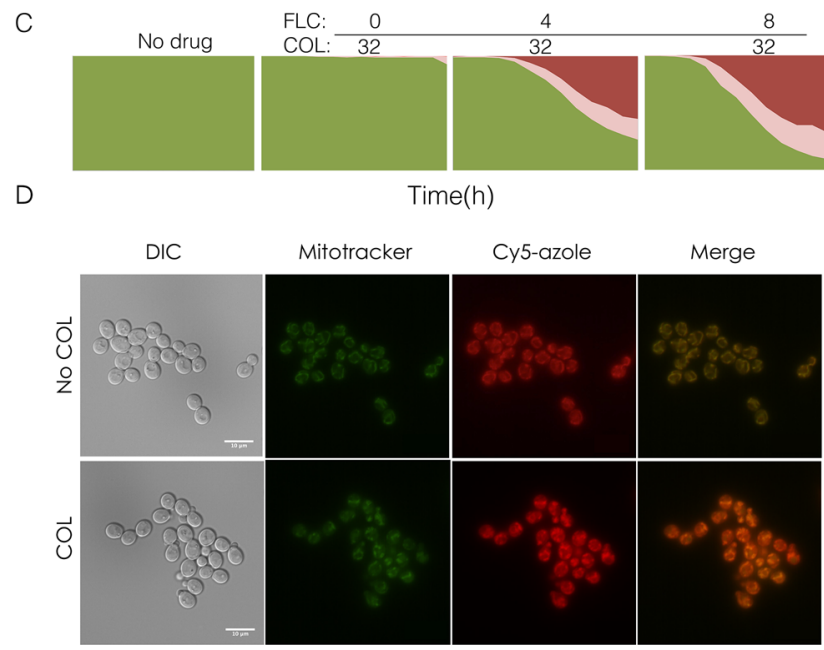

Figure 3. FLC+COL combination increases cell permeability, death, and fluconazole uptake. (A) Microscopy of cells treated with $0.25 \mu \mathrm{g} /$ $\mathrm{mL}$ FLC (as in Figure 2A) and stained with PI. Green arrow, live cells; pink arrow, permeable cells; red arrow, dead cells. DIC Images overlaid on mCherry channel. Bar, $10 \mu \mathrm{m}$ (143px). Images were taken after $24 \mathrm{~h}$ of growth in the absence or presence of FLC. (B) PI permeabilization after $3 \mathrm{~h}$ of drug exposure. Increase in cell permeability over time for no drug, $32 \mu \mathrm{g} / \mathrm{mL}$ COL and $4 \mu \mathrm{g} / \mathrm{mL}$ FLC $+32 \mu \mathrm{g} / \mathrm{mL} \mathrm{COL}$. $Y$-axis represents number of cells, and $X$-axis represents PI intensity in $3 \mathrm{~h}$ exposure time point. (C) Following drug exposure for $3 \mathrm{~h}$, logarithmic cultures were analyzed at $15 \mathrm{~min}$ interval, and cells were classified as live (green), permeable (pink), or dead (red) using gating thresholds as described in the text. Flow cytometry of PI stained for $3 \mathrm{~h}$, at 15 min intervals. Increased levels of permeable cells (pink) were particularly evident in FLC+COL treated cultures. Left panel, no drug; right three panels, cells exposed to 32 $\mu \mathrm{g} / \mathrm{mL}$ COL in the presence of 0,4 , or $8 \mu \mathrm{g} / \mathrm{mL}$ FLC. Examples of similar experiments at different COL concentrations are in Figure S7. Green, live, PI-impermeable cells; pink, PI-permeable cells; red, highly PI-permeable dead cells. (D) Fluorescence microscopy cells treated with Cy5-azole $(1 \mu \mathrm{g} / \mathrm{mL})^{39}$ and $32 \mu \mathrm{g} / \mathrm{mL} \mathrm{COL}$ and then stained with Mitotracker green, a dye that must cross the plasma membrane to stain mitochondrial membranes, for $30 \mathrm{~min}$. Size bar is $10 \mu \mathrm{m}$.

Colistin Synergizes with Mutants in the Ergosterol Biosynthesis Pathway. Colistin generally permeabilizes the membranes of Gram-negative bacteria due to its high LPS affinity and is therefore far less effective for Gram-positive bacteria and eukaryotic membranes. Furthermore, COL does not synergize with intracellular drugs such as 5-fluorocytosine (Figure S3); thus, the mechanism of synergy with FLC cannot be simply because COL increases yeast membrane permeability. However, it was possible that COL has a secondary effect that simply synergizes with azole antifungals. To test the hypothesis that FLC causes membrane defects that synergize directly with colistin-mediated membrane permeabilization, we asked if C. albicans mutants lacking genes in the yeast membrane ergosterol synthesis pathway ${ }^{42,43}$ (e.g., ERG2, ERG3, ERG4, ERG5, ERG6, ERG11, and ERG24) are sensitive to $\mathrm{COL}$ in the absence of FLC (Figure $4 \mathrm{~A}$ ).
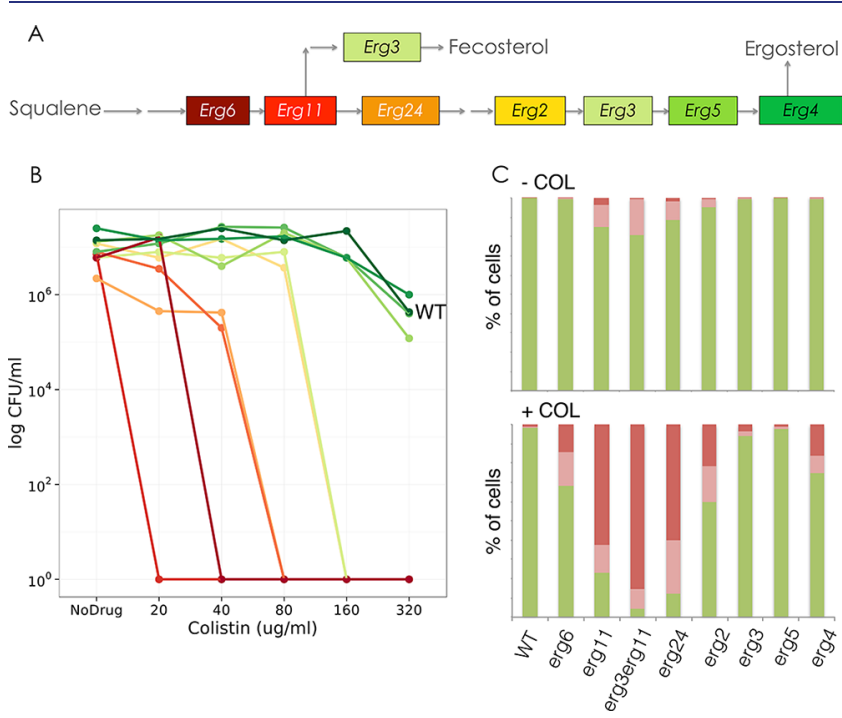

Figure 4. Colistin is cidal to mutants defective in early stages of ergosterol biosynthesis. (A) General scheme of the C. albicans ergosterol pathway ${ }^{43}$ (B) Analysis of subpopulation growth for ergosterol biosynthesis mutants from 0 to $320 \mu \mathrm{g} / \mathrm{mL}$ of colistin for $24 \mathrm{~h}$. Colors correspond to panel (A), with the wild-type parent strain shown in the darkest shade of green. (C) Mutations in some ERG genes cause increased cell permeability (top panel), that results in increased cell death upon exposure to COL $(64 \mu \mathrm{g} / \mathrm{mL})$. Proportion $(0-100 \%)$ of live (green), dead (red), and permeable (pink) cells in the absence (upper panel) and presence (lower panel) of COL for 16 h. Parental and erg mutant strains (with colors indicated in (A)) were stained with PI and fluorescence was measured by flow cytometry. Live cells (no PI staining (<239 AU), green), permeable cells (low PI staining (>239 and <8931 AU, pink), and dead (high PI staining (>8931 AU, red) with color scheme as in Figure 3C.

Indeed, colistin reduced the growth of ergosterol biosynthetic mutants (erg11, erg3erg11, erg24, and $\operatorname{erg} 2)$. This suggests that it is changes in membrane ergosterol that make cells more sensitive to colistin. Less dramatic effects were evident with mutants encoding enzymes further downstream in the ergosterol biosynthesis pathway.

FLC resistance and tolerance of the ERG mutants was assessed with disk diffusion assays in the absence or presence of COL (Figure S8A). Strains with erg6 or erg11 mutations were resistant to FLC and were hypersensitive to COL (no growth at all in the plate). Other erg mutants were more susceptible to FLC and less sensitive to COL (Figure S8), roughly as a function of their distance from erg11 in the pathway. Similar results were seen when comparing the proportion of cells inhibited as a function of COL concentration (Figure 4B) using a population analysis profile assay (Figure $4 \mathrm{~B}$ ). Together, these results indicate that the depletion of ergosterol, either through azole treatment or relevant erg mutations, increases the sensitivity of $C$. albicans cells to COL. In addition, they highlight that the mechanism of FLC+COL synergy is not due to increased amounts of intracellular FLC. Rather, reduced membrane ergosterol appears to increase cell vulnerability to $\mathrm{COL}$, presumably because of the altered membrane composition. 

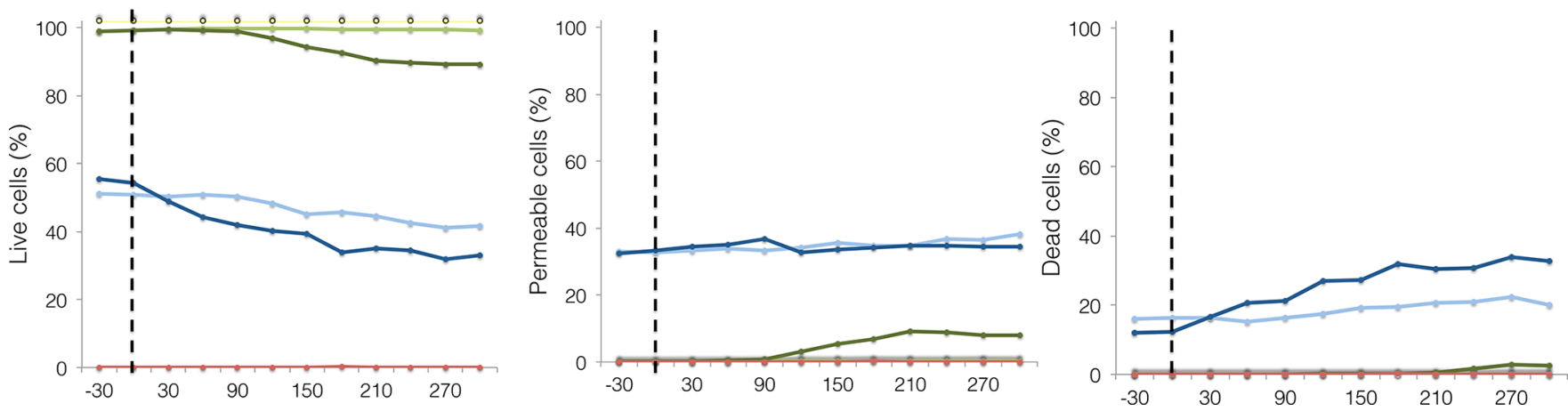

Figure 5. Order of addition of the two drugs affects the dynamics of FLC+COL cidality. SC5314 cells initially were pre-exposed to one drug; in all cases, $10 \mu \mathrm{g} / \mathrm{mL} \mathrm{FLC} \mathrm{or} 32 \mu \mathrm{g} / \mathrm{mL}$ COL was used in preincubation. After $16 \mathrm{~h}$ of pre-exposure, one drug was added $(10 \mu \mathrm{g} / \mathrm{mL} \mathrm{FLC} \mathrm{or} 32 \mu \mathrm{g} / \mathrm{mL}$ $\mathrm{COL}$ ) together with PI, and intracellular PI staining was measured at $30 \mathrm{~min}$ intervals. The proportions of live cells (intracellular PI staining < 239 AU, left), permeable cells (PI staining > 239 and < 8940 AU, center), and dead cells (PI staining > 8940 AU, right) are illustrated. Black dashed line indicates the time that the second drug was added $(t=0)$. Cells pre-exposed to COL (light green) to which FLC was added (dark green). The proportion of live cells dropped after $>120 \mathrm{~min}$. Cells pre-exposed to FLC (lighter blue) to which COL was added (dark blue). Upon the addition of COL, the proportion of live cells dropped almost immediately, within $<60 \mathrm{~min}$. Note that the time required for reduced permeability in stationary cells, here, was longer here than the time required in log phase cells in Figure 4C. The "no drug" data was identical to the COL line and is illustrated slightly above it to ensure it is visible. The dead cell control (cells fixed with ethanol) is shown as a dark red line.

To ask if colistin increases cell death in the erg mutants, as it does with FLC, we quantified intracellular PI levels in the erg mutants using flow cytometry. In the absence of drugs, almost all cells were alive and impermeable. In the $\operatorname{erg} 6, \operatorname{erg} 11$, and erg24 mutants, there was a small proportion of permeable cells (up to $10 \%$ ) and very small proportions of dead cells (Figure 4C). Importantly, adding COL to these mutants greatly increased the proportion of dead cells $(\sim 16-60 \%)$, with more modest increases in the proportion of permeable cells $(\sim 18-$ $27 \%$, Figure 4C).

The analysis of erg mutants provides interesting insights into the role of ERG3. First, while the erg3 mutant grew in the presence of FLC alone, it grew slowly in general and, when COL was present, the region near the FLC disk was highly sensitive to COL (Figure S8A). This is reminiscent of the clearance of tolerance by other adjuvants in wild-type cells and suggests Erg3 has a more prominent role in FLC tolerance than in bona fide resistance. ${ }^{44,45}$ However, unlike wild-type cells, erg3 mutants remained largely viable in the presence of FLC+COL, while $\operatorname{erg} 11$ erg 3 mutants, like erg11 mutants, were largely killed by COL (Figure 4B and C). This indicates that erg11 is epistatic to erg3 and that erg3 mutations do not rescue the sensitivity to COL conferred by erg11 deletion. Rather, it appears that the sensitivity of wild-type cells to FLC+COL is largely a function of ergosterol depletion and is not highly affected by the ability of Erg3 to produce toxic sterol intermediates. Taken together, these results imply that COL not only increases the amount of FLC that enters cells (Figure 3) but also permeabilizes, and ultimately kills, cells whose membranes have reduced ergosterol content (Figure 4).

Colistin Acts More Rapidly on Fluconazole Pretreated Cells. Fluconazole inhibits ergosterol biosynthesis by inhibiting the lanosterol $14 \alpha$-demethylase encoded by ERG11; however, ergosterol depletion requires several hours to slow growth and affect cell morphology. ${ }^{46}$ Since the combination of COL with FLC increased FLC uptake, cell permeabilization, and death, and since this is a consequence of ergosterol depletion, we next asked whether the dynamics of colistin's mechanism of action were faster than those of the mechanism of action of FLC. We compared the activity of COL added to fluconazole-pretreated cells with the activity of FLC added to colistin-pretreated cells by measuring PI levels over time after the addition of the second drug. Cells were $16 \mathrm{~h}$ in medium with the first drug and then we added medium without drug, with COL or FLC alone, or with both drugs together. PI intensity was measured $5 \mathrm{~h}$ after the addition of the second drug.

As expected, control cells exposed to no drug or to COL alone were not permeable to PI (Figure 5). Adding COL to cells pre-exposed to FLC (Figure 5), or to cells initially treated with FLC+COL (Figure 5), reduced viability within the first 30 min of treatment (Figure 5). By contrast, when adding FLC to cells pre-exposed to COL, growth reduction was seen only after $\sim 90$ min (Figure 5). Importantly, when COL was added to cells initially exposed to FLC, the reduction in viability occurred before the first measurement (at $30 \mathrm{~min}$ following the addition of COL) (Figure 5). Thus, COL rapidly permeabilizes cells pretreated with FLC more rapidly than it permeabilizes cells when added together with FLC. This suggests that COL not only increases FLC entry into cells, but that COL may have a more dramatic effect on viability in cells depleted for ergosterol.

Colistin Interacts with Membrane Phospholipids. While COL specifically binds bacterial lipopolysaccharide (LPS) in Gram-negative bacteria, in Gram-positive bacteria, it acts as a positively charged detergent, albeit at much higher concentrations than those required to eradicate Gram-negative pathogens. ${ }^{47}$ To ask if the antifungal activity of COL also is dependent upon its peptide charge, we tested three additional membrane-disrupting antimicrobials with different net charges for their ability to synergize with FLC (Figure S9). Similar to COL (charge $+5^{47}$ ), RB163, a cationic amphiphile-derived from the aminoglycoside antibiotic tobramycin ${ }^{48}$ (compound 3 in ref 48) synergized with FLC (FICI $=0.28$ with $0.125 \mu \mathrm{g}$ / $\mathrm{mL}$ FLC and $4 \mu \mathrm{g} / \mathrm{mL} \mathrm{RB} 163)$. By contrast, daptomycin $(\text { charge }-3)^{49}$ (Figure S9C) did not augment the activity of FLC. These results are consistent with the idea that, as for Gram-positive bacteria, in C. albicans, positive charge may be an important feature required for COL to disrupt ergosteroldepleted membranes.

COL binds with high affinity to LPS, a lipid absent from eukaryotic membranes. ${ }^{50}$ To ask if COL nonspecifically binds 
negatively charged membrane lipids present in yeast membranes, we performed a fluorescence displacement assay that discriminates between subtle differences in the binding of small molecules to the lipid A of core LPS, as well as to other phospholipids (see Methods). Indeed, COL was able to bind to phosphatidylinositol (PI), phosphatidyl-L-serine, and phosphatidylethanolamine, albeit with affinities 2-fold lower than its affinity for LPS (Figure S10). This supports the idea that COL has the potential to bind eukaryotic lipids in the plasma membrane. Altogether, it suggests that COL binds fungal plasma membranes to a greater degree when they are depleted of ergosterol, generating increased permeability to antifungal drugs, vital dyes, and other intracellular stains. Thus, we propose that COL, when combined with FLC, acts synergistically and increases drug cidality via the permeabilization of ergosterol-depleted membranes.

\section{DISCUSSION}

This study addressed the mechanism by which clinically feasible concentrations of COL, a potent anti-Gram-negative lipopeptide antibiotic, enhance the antifungal activity of fluconazole, the most widely used antifungal drug. We first confirmed earlier reports ${ }^{29,30}$ that colistin indeed synergizes with fluconazole against a range of $C$. albicans isolates, as well as against other non-albicans Candida species although the synergy with azoles is weaker than the synergy with echinocandins. Importantly, the effect of colistin on fluconazole tolerance is far more pronounced than that on resistance. Furthermore, the amount of colistin required to augment fluconazole and cause cell damage and death $(2 \mu \mathrm{g}$ colistin, Figure 2A and B) is well within the range of colistin concentrations used to treat patients with bacterial infections, $^{51,52}$ a critical distinction from many combination therapies that work in vitro but are not amenable to clinical use because of high toxicity in mammals. Consistent with this, colistin was particularly effective at augmenting the effect of fluconazole on a highly tolerant $C$. albicans isolate. Colistin also increased cell permeability and death in cells depleted for ergosterol, either by azole drugs or by mutations affecting critical steps in ergosterol biosynthesis. Finally, colistin can bind eukaryotic membrane lipids. We propose that the mechanism by which colistin exerts its antifungal activity is likely similar to its activity in Gram-positive bacteria: via membrane permeabilization that is dependent upon the highly cationic nature of the peptide and the negative charge of membrane. Thus, we posit that colistin binds and disrupts eukaryotic membranes more effectively if they are depleted of ergosterol and/or if plasma membrane integrity is perturbed.

Colistin Largely Reduces Fluconazole Tolerance, In Vitro and In Vivo. By directly assaying tolerance as well as resistance, the colistin-mediated reduction in fluconazole resistance was relatively modest: an average of $0.4 \mathrm{~mm}$ increase in the radius of the zone of inhibition, irrespective of the initial susceptibility level of the strain. Nonetheless, fluconazole enables colistin to affect fungal membranes resulting in cell death instead of cell arrest, and colistin reduced fluconazole tolerance to approximately basal levels, such that the original FoG level in FLC correlated with the reduction in FoG level in fluconazole plus colistin $\left(R^{2}=0.91\right)$. This result was seen with diverse $C$. albicans and non-albicans Candida isolates and is similar to what was previously seen with other adjuvant drugs when combined with fluconazole. ${ }^{7}$ Based on a study of patient isolates with high and low tolerance levels, ${ }^{7}$ fluconazole plus colistin, like other fluconazole-adjuvant combinations, would be most effective for treating infections caused by isolates with high fluconazole tolerance. Indeed, the fluconazole plus colistin combination increased the survival of $G$. mellonella infected with high tolerance strains most dramatically. Accordingly, the use of combination approaches that largely affect tolerance would require that clinical assays measure not only drug resistance, but also tolerance quantitatively, whether by disk assays analyzed by diskImageR or by broth microdilution assays. ${ }^{7,10,11}$

Colistin Increases Cell Permeability and Cidality of Ergosterol-Depleted Cells. Adding colistin to fluconazole increases the proportion of dead and PI-permeable cells in a concentration-dependent manner (Figure 3C). Furthermore, the fluconazole plus colistin combination is cidal, at drug concentrations as low as $0.25 \mu \mathrm{g} / \mathrm{mL}$ of fluconazole with $2 \mu \mathrm{g} /$ $\mathrm{mL}$ colistin (Figure 2), as determined by replica plating (Figure S2) as well as PI staining (Figures 2C and 3). Importantly, we found that PI staining could be used to identify permeable, yet viable, cells in addition to the classic distinctions made between live (unstained) and dead (brightly stained) cells. The interpretation of permeability in the low-tointermediate level of intracellular PI staining, is based upon cell refractivity and morphology, as well as on colony counts that suggest these cells continue to grow and form colonies. Nonetheless, we cannot rule out the possibility that at least some of these cells may be on their way to cell death. Whether they necessarily die or are able to recover remains to be determined.

The ability of colistin to permeabilize cells is associated with its ability to kill them. This appears to be due, in part, to colistin increasing the ability of azole probes to enter cells. In addition, in cells pretreated with fluconazole, COL accelerates cell permeability and mortality within $30 \mathrm{~min}$ (Figure 5). Similarly, cells lacking enzymes critical for ergosterol synthesis die when colistin is added (Figure 4) and this occurs via a cell permeabilization that appears similar to that seen with fluconazole plus colistin. Consistent with this, in Burkholderia cepacia, disruption of genes that encode enzymes required for the synthesis of hopinoids, analogues of eukaryotic steroids, are far more sensitive to polymyxin $B{ }^{53}$ Taken together, these results indicate that the azole treated cells are more sensitive to colistin because not only because colistin increases the intracellular fluconazole concentration, but because ergosterol depletion by fluconazole renders the cells more vulnerable to permeabilization by colistin.

We propose that the synergism of fluconazole with colistin occurs through a series of steps. First, fluconazole inhibits ergosterol biosynthesis, resulting in the depletion of membrane ergosterol. Second, ergosterol depletion alters membrane properties, making the membrane more susceptible to colistin-mediated membrane permeabilization, thereby increasing the intracellular concentrations of azoles and other molecules. Third, the detergent activity of COL permeabilizes, and thereby kills, more cells. Importantly, these synergistic activities occur in a dose-dependent manner, such that colistin can be used together with fluconazole and other azoles at low, clinically feasible, concentrations.

\section{CONCLUSION}

Colistin synergizes with fluconazole to permeabilize cell membranes, which leads to higher cidality with drug combinations used at low, clinically relevant concentrations. 
The drug combination is particularly effective against isolates that exhibit fluconazole tolerance, both in vivo and in vitro, which is achieved by activation of stress response pathways and reduction in intracellular drug concentrations. ${ }^{7}$ The interaction appears to be due to colistin binding plasma membrane lipids and is more effective in cells depleted of ergosterol, either pharmacologically (via an azole antifungal) or genetically, via mutations in ergosterol biosynthesis.

\section{METHODS}

Growth Conditions. Strains used in this study are listed in Table 1. Experiments were conducted with C. albicans standard lab strain SC5314, unless noted otherwise. Cells were grown to log phase in liquid casitone (casitone, yeast extract, sodium citrate dehydrate, glucose plus $40 \mathrm{mg} / \mathrm{L}$ adenine and $80 \mathrm{mg} / \mathrm{L}$ uridine; Sigma). Cultures were shaken at $30{ }^{\circ} \mathrm{C}$ in $5 \mathrm{~mL}$ of YPAD overnight. Drug-exposed cultures were diluted 1:100 for $2-3 \mathrm{~h}$ in casitone followed by drug addition. Drugs were diluted in water (posaconazole (Sigma-Aldrich SML2287, $>98 \%$ ), colistin (Glentham Life Sciences GA9867, $\geq 19000$ U/ $\mathrm{mg}$ ), amphotericin B (TOKU-E, $\geq 95 \%$ ), 5-fluorocytosine (Sigma-Aldrich F7129, $\geq 99 \%$ ); ethanol (terbinafine T8826, $\geq 98 \%$ ), fluconazole (Sigma-Aldrich F8929, $\geq 98 \%$, ketoconazole (Sigma-Aldrich K1003, $\geq 99 \%$ ), miconazole (Fischer Bioreagents, 98\%), clotrimazole (Glentham Life Sciences, GA8137), caspofungin diacetate (Sigma-Aldrich SML0425, $\geq 19000 \mathrm{IU} / \mathrm{mg}$ ), anidulafungin (Sigma-Aldrich SML2288, $\geq 97 \%$ ) myriocin (Sigma-Aldrich M1175, $\geq 98 \%$ ), amphotericin B (A2411, 80\%), daptomycin (Sigma-Aldrich D2446, $\geq 90 \%), \mathrm{RB}^{463^{48}}(\geq 95 \%)$ ) or DMSO (natamycin, SigmaAldrich, $\geq 95 \%$ ). Casitone solid media (casitone liquid plus 10 $\mathrm{g} / \mathrm{L}$ agar (Formedium, Ltd.)) was used for the disk assay method. Colistin (GA9867, Glentham Life Sciences, $\geq 19000$ $\mathrm{U} / \mathrm{mg}$ ) was added to agar media at a final concentration of 64 $\mu \mathrm{g} / \mathrm{mL}$.

Disk Assays. Strains were streaked from frozen culture onto YPAD agar and incubated overnight at $30{ }^{\circ} \mathrm{C}$. Two to three colonies were picked into $1 \mathrm{~mL}$ of $1 \times$ PBS solution, and optical density $\left(\mathrm{OD}_{600}\right)$ was determined with an Infinite M200 PRO Tecan instrument. $\mathrm{OD}_{600}$ was adjusted to 0.01 ( $10^{6}$ cells/ $\mathrm{mL})$ through dilution with $1 \times \mathrm{PBS}$, and $200 \mu \mathrm{L}$ of diluted culture from each strain was plated onto $15 \mathrm{~mL}$ casitone plates and spread using sterile beads ( $3 \mathrm{~mm}$, Fisher Scientific). After the plates had dried, a single $25 \mu \mathrm{g}$ drug disk (6 mm diameter, Becton, Dickinson and Company, USA) was placed in the center of each plate. Plates were incubated at $30{ }^{\circ} \mathrm{C}$ for $48 \mathrm{~h}$. Analyses of RAD and FoG were done by using the diskImageR script. ${ }^{10}$

Population Analysis Profiling Assays. Fresh colonies (2-3) were picked from strains grown overnight on YPAD plates into $1 \mathrm{~mL}$ of $10 \%$ glycerol in 96-well plates, and cells were diluted to $10^{6}$ cells $/ \mathrm{mL}$ based on $\mathrm{OD}_{600}$ measurements, followed by 10 -fold dilution series to reach 1000 cells $/ \mathrm{mL}$. A volume of $10 \mu \mathrm{L}$ was spotted to plates containing different concentrations of COL or FLC ranging from 0 to $320 \mu \mathrm{g} / \mathrm{mL}$. Cells were counted manually, and the number of cells per milliliter was calculated according to the dilutions and plotted using $\mathrm{R}$ software (ggplot2).

Checkerboard Assays and Growth Curves. Two to three colonies of strain SC5314 were picked into $1 \times$ PBS buffer, $\mathrm{OD}_{600}$ was adjusted to $0.01\left(10^{6}\right.$ cells $\left./ \mathrm{mL}\right)$ with $1 \times$ PBS, and cultures were then diluted to $10^{3}$ cells $/ \mathrm{mL}$ in casitone media. Drugs were added in a double dilution grid ranging from 0 to $128 \mu \mathrm{g} / \mathrm{mL}$ in 96 flat-well plate (BND003C, ThermoFisher Scientific). For growth curves, checkerboard assay plates as above were incubated in a Tecan Infinite instrument for $48 \mathrm{~h}$ in $30{ }^{\circ} \mathrm{C}$ with shaking. $\mathrm{OD}_{600}$ was read every $15 \mathrm{~min}$. $\mathrm{OD}_{600}$ at $24 \mathrm{~h}$ was plotted with Java Treeview software. FICI calculation was calculated as $\operatorname{MIC}\left(A_{B}\right) /$ $\operatorname{MIC}(\mathrm{A})+\operatorname{MIC}\left(\mathrm{B}_{\mathrm{A}}\right) / \mathrm{MIC}(\mathrm{B}) ; \operatorname{MIC}\left(\mathrm{A}_{\mathrm{B}}\right)-\mathrm{MIC}_{50}$ of drug $A$ in the presence of drug $B ; \operatorname{MIC}(A)-M_{50}$ of drug $A$; $\operatorname{MIC}\left(B_{A}\right)-M_{50}$ of drug $B$ in the presence of drug $A$; $\mathrm{MIC}(\mathrm{B})-\mathrm{MIC}_{50}$ of drug B. FICI $\geq 0.5$ was interpreted as synergy. ${ }^{34}$

CFU Count. Colony forming units (CFUs) were used to infer the cidality of fluconazole-colistin combinations at several concentrations. SC5314 was grown overnight on YPD agar at $30{ }^{\circ} \mathrm{C}$, and a checkerboard assay as described above was performed. After $\mathrm{OD}_{600}$ was measured, $5 \mathrm{~mL}$ from the relevant wells was serially diluted into YPD and plated onto YPD agar such that individual colonies could be enumerated. Colonies were counted, and final CFU was determined, following a $48 \mathrm{~h}$ incubation at $30{ }^{\circ} \mathrm{C}$.

Permeability Assay. Cells were grown in $3 \mathrm{~mL}$ liquid casitone media with shaking at $30^{\circ} \mathrm{C}$ overnight. Cultures were diluted 1:100 and incubated for $2 \mathrm{~h}$ at $30^{\circ} \mathrm{C}$ prior to initiating drug exposure (no drug, $32 \mu \mathrm{g} / \mathrm{mL} \mathrm{COL}, 10 \mu \mathrm{g} / \mathrm{mL}$ FLC, and both drugs together at these concentrations) at $30{ }^{\circ} \mathrm{C}$ with shaking. Samples collected over $16 \mathrm{~h}$ of growth were stained with propidium iodide as follows. A volume of $20 \mu \mathrm{L}$ from each culture was added to $180 \mu \mathrm{L}$ of TE 50:50 buffer $(50 \mathrm{mM}$ TrisHCl Sigma-Aldrich) such that the final PI concentration was $100 \mu \mathrm{g} / \mathrm{mL}$. Flow cytometry data were collected from 5000-35 000 cells per time point using B2 laser excitation at $488 \mathrm{~nm}$ and emission at $614 / 50 \mathrm{~nm}$ on a MACSQuant Analyzer 16 flow cytometer. Analysis was performed using FlowJo 8.7 software.

Galleria Mellonella Survival Assay. The larvae of the wax moth G. mellonella were obtained from Live Foods (U.K.). Larvae were kept at room temperature $(\sim 20 \mathrm{C})$ and used within 3 days of arrival. Only healthy larvae, not showing any darkening, were used. Ten larvae were randomly selected for each group. The experiment was repeated five times $(N=50)$. C. albicans (YJB3015 (low FoG), YJB3016 (low FoG), and 3023 (high FoG)) were grown overnight at $30{ }^{\circ} \mathrm{C}$ on YPD agar. A final inoculum size of $5 \times 10^{6} \mathrm{CFU} / \mathrm{mL}$ as determined by $\mathrm{OD}_{600}$ was prepared by diluting a sweep of colonies into YPD liquid. A Hamilton syringe with a 28G needle was used to inject each larvae with $10 \mu \mathrm{L}$ of the inoculum $\left(5 \times 10^{4} \mathrm{CFU}\right)$ via the bottom left proleg. Larvae were incubated at $30{ }^{\circ} \mathrm{C}$ for $2 \mathrm{~h}$ prior to a second injection into the bottom right proleg of either water, FLC $(1.25 \mu \mathrm{g} / \mathrm{mL})$, COL $(80 \mu \mathrm{g} / \mathrm{mL})$, or FLC $+\mathrm{COL}(1.25 \mu \mathrm{g} / \mathrm{mL}$ and $80 \mu \mathrm{g} / \mathrm{mL}$, respectively). Larvae were incubated at $30{ }^{\circ} \mathrm{C}$ for 5 days. Larval survival was assessed every $24 \mathrm{~h}$. A larva was considered dead if it had turned blackgray and did not respond to physical stimuli. A trauma control group (two injections of water) and drug-tolerance groups (one injection of a drug condition and one of water) were used as additional controls. A further control group that received no injections was also used. $100 \%$ of larvae in these control groups survived (data not shown). Statistical variation was determined using the log-rank test.

Assaying Sequential Addition of Drugs. Cells were grown in $3 \mathrm{~mL}$ of liquid casitone media with shaking at $30^{\circ} \mathrm{C}$ in tubes overnight. Cultures were diluted $1: 100$ and incubated for an additional $2 \mathrm{~h}$ at $30{ }^{\circ} \mathrm{C}$ followed by $\mathrm{OD}_{600}$ measurement 
with a TeCAN Infinite instrument. $\mathrm{OD}_{600}$ was adjusted to 0.01 $\left(10^{6}\right.$ cells $\left./ \mathrm{mL}\right)$ with casitone media, and cells were grown in four different conditions (no drug, $32 \mu \mathrm{g} / \mathrm{mLCOL}, 10 \mu \mathrm{g} / \mathrm{mL}$ FLC and both drugs) for $16 \mathrm{~h}$ at $30{ }^{\circ} \mathrm{C}$ with shaking. After 16 $\mathrm{h}$, the first measurement $(0 \mathrm{~min})$ was taken by adding $20 \mu \mathrm{L}$ of each culture to $180 \mu \mathrm{L}$ of TE $50: 50$ buffer $(50 \mathrm{mM}$ TrisHCl $\mathrm{pH} 8.0,50 \mathrm{mM}$ EDTA) containing PI at a concentration of $100 \mu \mathrm{g} / \mathrm{mL}$ (P4170 SIGMA Aldrich). At $30 \mathrm{~min}$, drugs were added. PI permeability was tested, as above, at 15 min intervals for $3 \mathrm{~h}$. Flow cytometry data were collected from 5000-35 000 cells per time point by using B2 laser excitation (excitation at $488 \mathrm{~nm}$ and emission at 614/50 nm) on a MACSQuant flow cytometer. Analysis was performed using FlowJo 8.7 software.

Staining. Log phase cell cultures were exposed to different drugs at $30{ }^{\circ} \mathrm{C}$, for times indicated in figure legends. Cells were isolated from a log phase culture and warmed to $37{ }^{\circ} \mathrm{C}$. Mitotracker Green FM (c.n.M7514 ThermoFisher) was added to a final concentration of $1 \mathrm{mM}$. Cells were incubated in the dark for 0-120 min. Cells were then washed with $1 \times$ PBS buffer and resuspended in SDC medium ( $0.17 \%$ yeast nitrogen base with ammonium sulfate [Formedium], 2\% glucose) supplemented with amino and nucleic acids) ${ }^{66}$ containing 1 $\mathrm{mg} / \mathrm{mL}$ calcoflour white (by Sigma-Aldrich) for imaging each time point. DAPI (4',6-diamidino-2-phenylindole, SigmaAldrich) was suspended in double distilled water and added to cells at $10 \mu \mathrm{g} / \mathrm{mL}$ final concentration in PBS with cells at 25 ${ }^{\circ} \mathrm{C}$ for 5 min.

Time Course Imaging/Microscopy. Cells in time course experiments were washed and resuspended in SDC prior to being imaged on glass slides with glass coverslips. Images were collected using a Nikon Ti Eclipse microscope equipped with a Nikon 1006, 1.4 NA, 100× objective and a Zyla 5.5 sCMOS camera run by NIS elements Ar software. To image the stains, we used the following filter sets: MitoTracker Green, $470 \mathrm{~nm}$ excitation and 525/50 nm emission; calcofluor white and DAPI, $365 \mathrm{~nm}$ excitation and 460/50 nm emission; and AzoleCy5, $585 \mathrm{~nm}$ excitation and 630/75 $\mathrm{nm}$ emission.

Flow Cytometric Analysis of Azole-Cy5 Uptake. Cells were grown in $3 \mathrm{~mL}$ of liquid casitone medium at $30{ }^{\circ} \mathrm{C}$ with shaking overnight. Cultures were diluted 1:100 and incubated for an additional $2 \mathrm{~h}$ at $30^{\circ} \mathrm{C}$. Azole-Cy5 was added $(1 \mu \mathrm{g} / \mathrm{mL}$ final concentration), and cultures were incubated for an additional $0-180 \mathrm{~min}$ with shaking at $30{ }^{\circ} \mathrm{C}$. For for uptake analysis, cells were harvested every $30 \mathrm{~min}$ and diluted 1:10 TE 50:50 buffer (50 mM TrisHCl pH 8.0, $50 \mathrm{mM}$ EDTA), using 25 000-35000 cells per time point on a MACSQuant flow cytometer using $561 \mathrm{~nm}$ excitation and 661/20 nm emission (Y3 laser). Data were analyzed with FlowJo8.7 software.

Lipid Binding Assay. Lipid binding was measured using a fluorescence displacement assay that measures the fluorescent signal of BODIPY-cadaverine and discriminates between subtle differences in the binding of small molecules to the lipid A core of lipopolysaccharide (LPS). It measures competitive displacement by compounds displaying lipid A affinity. As BODIPcadaverine binds to other phospholipids, this fluorescence displacement assay can be used to measure the binding of small molecules to phospholipids other than LPS. ${ }^{67,68}$

Stock solutions of lipids (Sigma-Aldrich) (LPS $5 \mathrm{mg} / \mathrm{mL}$ in $\mathrm{H}_{2} \mathrm{O}$; PE, $5 \mathrm{mg} / \mathrm{mL}$ in DMSO $/ \mathrm{H}_{2} \mathrm{O}$; $\mathrm{PI}, 5 \mathrm{mg} / \mathrm{mL}$ in $\mathrm{H}_{2} \mathrm{O}$ and PS $1 \mathrm{mg} / \mathrm{mL}$ in $\left.\mathrm{H}_{2} \mathrm{O}\right)$ and BODIPY-TR-cadaverine $(500 \mu \mathrm{M})$ were prepared in Tris buffer $(\mathrm{pH} 7.4)$. Lipid stocks and BODIPY-TR-cadaverine stock were mixed and diluted in Tris buffer to a final volume of $100 \mathrm{~mL}$, yielding final concentrations of $50 \mu \mathrm{g} / \mathrm{mL}$ of lipid and $5 \mu \mathrm{M}$ BODIPYTR-cadaverine. To each well of the 96-well plate, $40 \mu \mathrm{L}$ of Tris buffer with COL or FLC was added using double dilutions starting from $2 \mathrm{mM}$, followed by the addition of $40 \mu \mathrm{L}$ of BODIPY-TR-cadaverine-lipid mixture. Fluorescence was measured on a TECAN Microplate reader (infinite F200 PRO) at $25{ }^{\circ} \mathrm{C}$ using excitation and emission wavelengths of 580 and $620 \mathrm{~nm}$, respectively (monochromatic band pass of 5 $\mathrm{nm}$ ). Data were collected from two independent experiments, with three replicates per experiment.

\section{ASSOCIATED CONTENT}

\section{SI Supporting Information}

The Supporting Information is available free of charge at https://pubs.acs.org/doi/10.1021/acsinfecdis.0c00721.

Disk diffusion assays for different Candida spp. isolates, additional azole antifungal drugs and other antifungal inhibitors in the absence and presence of colistin; itraconazole checkerboard assay; Cy5-azole uptake data; cell permeability with FLC and COL alone and in combination; fluorescence microscopy of $\mathrm{Cy} 5$-azole and Mitotracker green; FLC disk diffusion assays of strains defective in ergosterol biosynthesis with and without COL; checkerboard assays with antibacterial drugs; lipid binding assays (PDF)

\section{AUTHOR INFORMATION}

\section{Corresponding Author}

Judith Berman - Shmunis School of Biomedical and Cancer Research, George S. Wise Faculty of Life Sciences, Tel Aviv University, Ramat Aviv 6997801, Israel; (1) orcid.org/00000002-8577-0084; Email: jberman@tauex.tau.ac.il

\section{Authors}

Maayan Bibi - Shmunis School of Biomedical and Cancer Research, George S. Wise Faculty of Life Sciences, Tel Aviv University, Ramat Aviv 6997801, Israel

Sarah Murphy - Institute for Infection and Immunity, St George's University, London SW17 ORE, United Kingdom

Raphael I. Benhamou - School of Chemistry, Raymond and Beverly Sackler Faculty of Exact Sciences, Tel Aviv University, Ramat Aviv 6997801, Israel; 10 orcid.org/0000-00031743-0886

Alex Rosenberg - Shmunis School of Biomedical and Cancer Research, George S. Wise Faculty of Life Sciences, Tel Aviv University, Ramat Aviv 6997801, Israel

Adi Ulman - Shmunis School of Biomedical and Cancer Research, George S. Wise Faculty of Life Sciences, Tel Aviv University, Ramat Aviv 6997801, Israel

Tihana Bicanic - Institute for Infection and Immunity, St George's University, London SW17 ORE, United Kingdom; Clinical Academic Group in Infection, St George's Hospital NHS Trust, London SW17 OQT, United Kingdom

Micha Fridman - School of Chemistry, Raymond and Beverly Sackler Faculty of Exact Sciences, Tel Aviv University, Ramat Aviv 6997801, Israel; 이이.org/0000-0002-2009-7490

Complete contact information is available at:

https://pubs.acs.org/10.1021/acsinfecdis.0c00721

\section{Author Contributions}

M.B. and S.M. contributed equally. M.B. performed flow cytometry, microbiology, and microscopy experiments, ana- 
lyzed data, and contributed to manuscript preparation. S.M. performed animal and microbiology experiments, analyzed data, and contributed to manuscript preparation. R.I.B. performed and analyzed lipid binding assays, synthesized and tested alternative antibiotics, and helped edit the manuscript. A.R. performed microbiological assays. A.U. made important initial observations. T.B. edited the manuscript. M.F. contributed to planning the experiments and editing the manuscript. J.B. initiated and planned the project, analyzed data, and wrote and edited the manuscript.

\section{Notes}

The authors declare no competing financial interest.

\section{ACKNOWLEDGMENTS}

This work was supported by funding from the Israeli Ministry of Science Technology \#88555 to M.F. and J.B.; by the Israel Science Foundation Grant \#997/18 to J.B. and \#179/19 to M.F.; and by European Research Council (RAPLODAPT \#340087) to J.B. S.M. was funded through a St George's Hospital Charity Grant 19-20-001 to T.B.

\section{REFERENCES}

(1) Pfaller, M. A., and Diekema, D. J. (2007) Epidemiology of Invasive Candidiasis: A Persistent Public Health Problem. Clin. Microbiol. Rev. 20, 133-163.

(2) Tsay, S. V., Mu, Y., Williams, S., Epson, E., Nadle, J., Bamberg, W. M., Barter, D. M., Johnston, H. L., Farley, M. M., Harb, S., Thomas, S., Bonner, L. A., Harrison, L. H., Hollick, R., Marceaux, K., Mody, R. K., Pattee, B., Shrum Davis, S., Phipps, E. C., Tesini, B. L., Gellert, A. B., Zhang, A. Y., Schaffner, W., Hillis, S., Ndi, D., Graber, C. R., Jackson, B. R., Chiller, T., Magill, S., and Vallabhaneni, S. (2020) Burden of Candidemia in the United States, 2017. Clin. Infect. Dis., e449-e453.

(3) Kim, J. H., Chan, K. L., Cheng, L. W., Tell, L. A., Byrne, B. A., Clothier, K., and Land, K. M. (2019) High Efficiency Drug Repurposing Design for New Antifungal Agents. Methods Protoc. 2,

(4) Butts, A., Palmer, G. E., and Rogers, P. D. (2017) Antifungal Adjuvants: Preserving and Extending the Antifungal Arsenal. Virulence. 8, 198-210.

(5) Berkow, E., and Lockhart, S. (2017) Fluconazole Resistance in Candida Species: A Current Perspective. Infect. Drug Resist. 10, 237245.

(6) Nakayama, H., Nakayama, N., Arisawa, M., and Aoki, Y. (2001) In Vitro and in Vivo Effects of 14alpha-Demethylase (ERG11) Depletion in Candida glabrata. Antimicrob. Agents Chemother. 45, 3037-3045.

(7) Rosenberg, A., Ene, I. V., Bibi, M., Zakin, S., Segal, E. S., Ziv, N., Dahan, A. M., Colombo, A. L., Bennett, R. J., and Berman, J. (2018) Antifungal Tolerance Is a Subpopulation Effect Distinct from Resistance and Is Associated with Persistent Candidemia. Nat. Commun. 9, 2470

(8) Berman, J., and Krysan, D. J. (2020) Drug Resistance and Tolerance in Fungi. Nat. Rev. Microbiol. 18, 319-331.

(9) Revie, N. M., Iyer, K. R., Robbins, N., and Cowen, L. E. (2018) Antifungal Drug Resistance: Evolution, Mechanisms and Impact. Curr. Opin. Microbiol. 45, 70-76.

(10) Gerstein, A. C., Rosenberg, A., Hecht, I., and Berman, J. (2016) diskImageR: Quantification of Resistance and Tolerance to Antimicrobial Drugs Using Disk Diffusion Assays. Microbiology 162, $1059-1068$

(11) Astvad, K. M. T., Sanglard, D., Delarze, E., Hare, R. K., and Arendrup, M. C. (2018) Implications of the EUCAST Trailing Phenomenon in Candida tropicalis for the In Vivo Susceptibility in Invertebrate and Murine Models. Antimicrob. Agents Chemother. 62, 62.
(12) Levinson, T., Dahan, A., Novikov, A., Paran, Y., Berman, J., and Ben-Ami, R. (2021) Impact of Tolerance to Fluconazole on Treatment Response in Candida albicans Bloodstream Infection. Mycoses 64, 78-85.

(13) Mishra, N. N., Prasad, T., Sharma, N., and Gupta, D. K. (2008) Membrane Fluidity and Lipid Composition of Fluconazole Resistant and Susceptible Strains of Candida albicans Isolated from Diabetic Patients. Braz. J. Microbiol. 39, 219-225.

(14) Prasad, T., Chandra, A., Mukhopadhyay, C. K., and Prasad, R. (2006) Unexpected Link between Iron and Drug Resistance of Candida Spp.: Iron Depletion Enhances Membrane Fluidity and Drug Diffusion, Leading to Drug-Susceptible Cells. Antimicrob. Agents Chemother. 50, 3597-3606.

(15) Pasrija, R., Krishnamurthy, S., Prasad, T., Ernst, J. F., and Prasad, R. (2005) Squalene Epoxidase Encoded by ERG1 Affects Morphogenesis and Drug Susceptibilities of Candida albicans. J. Antimicrob. Chemother. 55, 905-913.

(16) Mansfield, B. E., Oltean, H. N., Oliver, B. G., Hoot, S. J., Leyde, S. E., Hedstrom, L., and White, T. C. (2010) Azole Drugs Are Imported by Facilitated Diffusion in Candida albicans and Other Pathogenic Fungi. PLoS Pathog. 6, No. e1001126.

(17) Boiron, P., Drouhet, E., Dupont, B., and Improvisi, L. (1987) Entry of Ketoconazole into Candida albicans. Antimicrob. Agents Chemother. 31, 244-248.

(18) Gong, Y., Li, T., Yu, C., and Sun, S. (2017) Candida albicans Heat Shock Proteins and Hsps-Associated Signaling Pathways as Potential Antifungal Targets. Front. Cell. Infect. Microbiol. 7, 520.

(19) Poirel, L., Jayol, A., and Nordmann, P. (2017) Polymyxins: Antibacterial Activity, Susceptibility Testing, and Resistance Mechanisms Encoded by Plasmids or Chromosomes. Clin. Microbiol. Rev. 30, 557-596.

(20) Falagas, M. E., Kasiakou, S. K., and Saravolatz, L. D. (2005) Colistin: The Revival of Polymyxins for the Management of Multidrug-Resistant Gram-Negative Bacterial Infections. Clin. Infect. Dis. 40, 1333-1341.

(21) Hancock, R. E. (1997) Peptide Antibiotics. Lancet 349, 418422.

(22) Loho, T., and Dharmayanti, A. (2015) Colistin: An Antibiotic and Its Role in Multiresistant Gram-Negative Infections. Acta Med. Indones. 47, 157-168.

(23) Spapen, H., Jacobs, R., Van Gorp, V., Troubleyn, J., and Honoré, P. M. (2011) Renal and Neurological Side Effects of Colistin in Critically Ill Patients. Ann. Intensive Care 1, 14.

(24) Parmar, A., Iyer, A., Vincent, C. S., Van Lysebetten, D., Prior, S. H., Madder, A., Taylor, E. J., and Singh, I. (2016) Efficient Total Syntheses and Biological Activities of Two Teixobactin Analogues. Chem. Commun. 52, 6060-6063.

(25) Sabnis, A., Klöckner, A., Becce, M., and Evans, L. E. Colistin Kills Bacteria by Targeting Lipopolysaccharide in the Cytoplasmic Membrane. bioRxiv, January 20, 2020. DOI: 10.1101/479618.

(26) Putker, F., Bos, M. P., and Tommassen, J. (2015) Transport of Lipopolysaccharide to the Gram-Negative Bacterial Cell Surface. FEMS Microbiol. Rev. 39, 985-1002.

(27) Yousfi, H., Ranque, S., Rolain, J.-M., and Bittar, F. (2019) In Vitro Polymyxin Activity against Clinical Multidrug-Resistant Fungi. Antimicrob. Resist. Infect. Control 8, 66.

(28) Schwarz, P., Bidaud, A.-L., and Dannaoui, E. (2020) In Vitro Synergy of Isavuconazole in Combination with Colistin against Candida auris. Sci. Rep. 10, 21448.

(29) Zeidler, U., Bougnoux, M.-E., Lupan, A., Helynck, O., Doyen, A., Garcia, Z., Sertour, N., Clavaud, C., Munier-Lehmann, H., Saveanu, C., and d'Enfert, C. (2013) Synergy of the Antibiotic Colistin with Echinocandin Antifungals in Candida Species. J. Antimicrob. Chemother. 68, 1285-1296.

(30) Zhai, B., Zhou, H., Yang, L., Zhang, J., Jung, K., Giam, C.-Z., Xiang, X., and Lin, X. (2010) Polymyxin B, in Combination with Fluconazole, Exerts a Potent Fungicidal Effect. J. Antimicrob. Chemother. 65, 931-938. 
(31) Nicholls, M. W. N. (1970) Polymyxin Sensitivity Of Candida tropicalis. J. Med. Microbiol. 3, 529-538.

(32) Avedissian, S. N., Liu, J., Rhodes, N. J., Lee, A., Pais, G. M., Hauser, A. R., and Scheetz, M. H. (2019) A Review of the Clinical Pharmacokinetics of Polymyxin B. Antibiotics (Basel, Switz.) 8, 31.

(33) Orhan, G., Bayram, A., Zer, Y., and Balci, I. (2005) Synergy Tests by $\mathrm{E}$ Test and Checkerboard Methods of Antimicrobial Combinations against Brucella melitensis. J. Clin. Microbiol. 43, 140143.

(34) Odds, F. C. (2003) Synergy, Antagonism, and What the Chequerboard Puts between Them. J. Antimicrob. Chemother. 52, 1.

(35) Wind, C. M., de Vries, H. J. C., and van Dam, A. P. (2015) Determination of in Vitro Synergy for Dual Antimicrobial Therapy against Resistant Neisseria gonorrhoeae Using Etest and Agar Dilution. Int. J. Antimicrob. Agents 45, 305-308.

(36) Sorlí, L., Luque, S., Segura, C., Campillo, N., Montero, M., Esteve, E., Herrera, S., Benito, N., Alvarez-Lerma, F., Grau, S., and Horcajada, J. P. (2017) Impact of Colistin Plasma Levels on the Clinical Outcome of Patients with Infections Caused by Extremely Drug-Resistant Pseudomonas aeruginosa. BMC Infect. Dis. 17, 11.

(37) Pacheco, T., Bustos, R.-H., González, D., Garzón, V., García, J.C., and Ramírez, D. (2019) An Approach to Measuring Colistin Plasma Levels Regarding the Treatment of Multidrug-Resistant Bacterial Infection. Antibiotics (Basel) 8 (3), 100.

(38) Ocampo, A., and Barrientos, A. (2011) Quick and Reliable Assessment of Chronological Life Span in Yeast Cell Populations by Flow Cytometry. Mech. Ageing Dev. 132 (6-7), 315-323.

(39) Benhamou, R. I., Bibi, M., Steinbuch, K. B., Engel, H., Levin, M., Roichman, Y., Berman, J., and Fridman, M. (2017) Real-Time Imaging of the Azole Class of Antifungal Drugs in Live Candida Cells. ACS Chem. Biol. 12, 1769-1777.

(40) Benhamou, R. I., Bibi, M., Berman, J., and Fridman, M. (2018) Localizing Antifungal Drugs to the Correct Organelle Can Markedly Enhance Their Efficacy. Angew. Chem., Int. Ed. 57 (21), 6230-6235.

(41) Benhamou, R. I., Jaber, Q. Z., Herzog, I. M., Roichman, Y., and Fridman, M. (2018) Fluorescent Tracking of the Endoplasmic Reticulum in Live Pathogenic Fungal Cells. ACS Chem. Biol. 13, $3325-3332$.

(42) Lv, Q.-Z., Yan, L., and Jiang, Y.-Y. (2016) The Synthesis, Regulation, and Functions of Sterols in Candida albicans: Well-Known but Still Lots to Learn. Virulence 7, 649-659.

(43) Sanglard, D., Ischer, F., Parkinson, T., Falconer, D., and Bille, J. (2003) Candida albicans Mutations in the Ergosterol Biosynthetic Pathway and Resistance to Several Antifungal Agents. Antimicrob. Agents Chemother. 47, 2404-2412.

(44) Luna-Tapia, A., Butts, A., and Palmer, G. E. (2019) Loss of C-5 Sterol Desaturase Activity in Candida albicans: Azole Resistance or Merely Trailing Growth? Antimicrob. Agents Chemother. 63, 63.

(45) Luna-Tapia, A., Willems, H. M. E., Parker, J. E., Tournu, H., Barker, K. S., Nishimoto, A. T., Rogers, P. D., Kelly, S. L., Peters, B. M., and Palmer, G. E. (2018) Loss of Upc2p-Inducible ERG3 Transcription Is Sufficient To Confer Niche-Specific Azole Resistance without Compromising Candida albicans Pathogenicity. MBio 9 (3), e00225-18.

(46) Harrison, B. D., Hashemi, J., Bibi, M., Pulver, R., Bavli, D., Nahmias, Y., Wellington, M., Sapiro, G., and Berman, J. (2014) A Tetraploid Intermediate Precedes Aneuploid Formation in Yeasts Exposed to Fluconazole. PLoS Biol. 12, No. e1001815.

(47) Benhamou, R. I., Shaul, P., Herzog, I. M., and Fridman, M. (2015) Di-N-Methylation of Anti-Gram-Positive AminoglycosideDerived Membrane Disruptors Improves Antimicrobial Potency and Broadens Spectrum to Gram-Negative Bacteria. Angew. Chem., Int. Ed. 54 (46), 13617-13621.

(48) Jaber, Q. Z., Benhamou, R. I., Herzog, I. M., Ben Baruch, B., and Fridman, M. (2018) Cationic Amphiphiles Induce Macromolecule Denaturation and Organelle Decomposition in Pathogenic Yeast. Angew. Chem., Int. Ed. 57 (50), 16391-16395.
(49) Heidary, M., Khosravi, A. D., Khoshnood, S., Nasiri, M. J., Soleimani, S., and Goudarzi, M. (2018) Daptomycin. J. Antimicrob. Chemother. 73, 1-11.

(50) Bialvaei, A. Z., and Samadi Kafil, H. (2015) Colistin, Mechanisms and Prevalence of Resistance. Curr. Med. Res. Opin. 31, 707-721.

(51) Karvanen, M., Plachouras, D., Friberg, L. E., Paramythiotou, E., Papadomichelakis, E., Karaiskos, I., Tsangaris, I., Armaganidis, A., Cars, O., and Giamarellou, H. (2013) Colistin Methanesulfonate and Colistin Pharmacokinetics in Critically Ill Patients Receiving Continuous Venovenous Hemodiafiltration. Antimicrob. Agents Chemother. 57, 668-671.

(52) Mohamed, A. F., Karaiskos, I., Plachouras, D., Karvanen, M., Pontikis, K., Jansson, B., Papadomichelakis, E., Antoniadou, A., Giamarellou, H., Armaganidis, A., Cars, O., and Friberg, L. E. (2012) Application of a Loading Dose of Colistin Methanesulfonate in Critically Ill Patients: Population Pharmacokinetics, Protein Binding, and Prediction of Bacterial Kill. Antimicrob. Agents Chemother. 56, 4241-4249.

(53) Malott, R. J., Steen-Kinnaird, B. R., Lee, T. D., and Speert, D. P. (2012) Identification of Hopanoid Biosynthesis Genes Involved in Polymyxin Resistance in Burkholderia multivorans. Antimicrob. Agents Chemother. 56, 464-471.

(54) De Las Penas, A. (2003) Virulence-Related Surface Glycoproteins in the Yeast Pathogen Candida glabrata Are Encoded in Subtelomeric Clusters and Subject to RAP1- and SIR-Dependent Transcriptional Silencing. Genes Dev. 17, 2245-2258.

(55) Sullivan, D., and Coleman, D. (1998) Candida dubliniensis: Characteristics and Identification. J. Clin. Microbiol. 36, 329-334.

(56) Bendel, C. M. (2003) Colonization and Epithelial Adhesion in the Pathogenesis of Neonatal Candidiasis. Semin. Perinatol. 27, 357364.

(57) Wu, W., Lockhart, S. R., Pujol, C., Srikantha, T., and Soll, D. R. (2007) Heterozygosity of Genes on the Sex Chromosome Regulates Candida albicans Virulence. Mol. Microbiol. 64, 1587-1604.

(58) MacCallum, D. M., Castillo, L., Nather, K., Munro, C. A., Brown, A. J. P., Gow, N. A. R., and Odds, F. C. (2009) Property Differences among the Four Major Candida albicans Strain Clades. Eukaryotic Cell 8, 373-387.

(59) Magwene, P. M., Kayçkıç, Ö., Granek, J. A., Reininga, J. M., Scholl, Z., and Murray, D. (2011) Outcrossing, Mitotic Recombination, and Life-History Trade-Offs Shape Genome Evolution in Saccharomyces cerevisiae. Proc. Natl. Acad. Sci. U. S. A. 108, 19871992.

(60) McEachern, M. J., and Blackburn, E. H. (1994) A Conserved Sequence Motif within the Exceptionally Diverse Telomeric Sequences of Budding Yeasts. Proc. Natl. Acad. Sci. U. S. A. 91, 3453-3457.

(61) Barker, K. S., Crisp, S., Wiederhold, N., Lewis, R. E., Bareither, B., Eckstein, J., Barbuch, R., Bard, M., and Rogers, P. D. (2004) Genome-Wide Expression Profiling Reveals Genes Associated with Amphotericin B and Fluconazole Resistance in Experimentally Induced Antifungal Resistant Isolates of Candida albicans. J. Antimicrob. Chemother. 54, 376-385.

(62) Marr, K. A., White, T. C., van Burik, J. A., and Bowden, R. A. (1997) Development of Fluconazole Resistance in Candida albicans Causing Disseminated Infection in a Patient Undergoing Marrow Transplantation. Clin. Infect. Dis. 25, 908-910.

(63) Selmecki, A., Gerami-Nejad, M., Paulson, C., Forche, A., and Berman, J. (2008) An Isochromosome Confers Drug Resistance in Vivo by Amplification of Two Genes, ERG11 and TAC1. Mol. Microbiol. 68, 624-641.

(64) Noble, S. M., and Johnson, A. D. (2005) Strains and Strategies for Large-Scale Gene Deletion Studies of the Diploid Human Fungal Pathogen Candida albicans. Eukaryotic Cell 4, 298-309.

(65) Vincent, B. M., Lancaster, A. K., Scherz-Shouval, R., Whitesell, L., and Lindquist, S. (2013) Fitness Trade-Offs Restrict the Evolution of Resistance to Amphotericin B. PLoS Biol. 11, No. e1001692. 
(66) Amberg, D. C., Burke, D. J., and Strathern, J. N. Methods in yeast genetics: a Cold Spring Harbor Laboratory course manual. 2005. Cold Spring Harbor Laboratory Press: Cold Spring Harbor, NY.

(67) Wood, S. J., Miller, K. A., and David, S. A. (2004) AntiEndotoxin Agents. 1. Development of a Fluorescent Probe Displacement Method Optimized for the Rapid Identification of Lipopolysaccharide-Binding Agents. Comb. Chem. High Throughput Screening 7, 239-249.

(68) Kolahi, K., Louey, S., Varlamov, O., and Thornburg, K. (2016) Real-Time Tracking of BODIPY-C12 Long-Chain Fatty Acid in Human Term Placenta Reveals Unique Lipid Dynamics in Cytotrophoblast Cells. PLoS One 11, No. e0153522. 